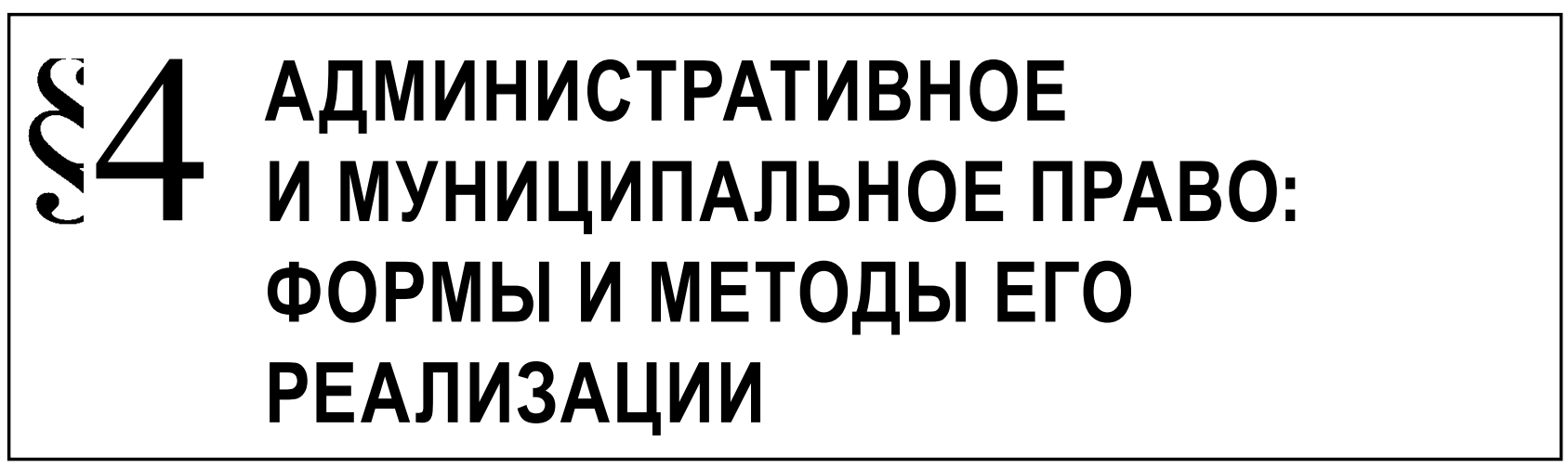

Котляров Ю.В.

\title{
ТЕНДЕНЦИИ РАЗВИТИЯ И АКТУАЛЬНЫЕ ПРОБЛЕМЫ НОРМАТИВНО-ПРАВОВОЙ БАЗЫ ТЕХНИЧЕСКОГО РЕГУЛИРОВАНИЯ В РОССИЙСКОЙ ФЕДЕРАЦИИ
}

\begin{abstract}
Аннотация. Автор подробно рассматривает такие аспекты темы как развитие нормативно - правовой базы технического регулирования в контексте развития экономических условий в Российской Федерации и актуальные проблемы законодательства в данной сфере. Особое внимание уделяется процессам совершенствования и формирования нормативно-правовой базы в сфере технического регулирования в рамках интеграционных процессов Таможенного союза, Евразийского экономического сообщества, гармонизации нормативно-правовой базы принципам Всемирной торговой организации, направленных на развитие экономики России и расширения внешнеэкономических связей. Методологической основой исследования является диалектический метод познания и системный подход. В процессе исследования использовались такие общенаучные методы как анализ, обобщение, синтез и прогнозирование. Основным выводом проведённого исследования является тот факт, что к настоящему времени сформирована обширная правовая база, способствующая фрормированию единого законодательства в срере технического регулирования, при этом определяющим фактором совершенствования законодательства о техническом регулировании являются интеграционные процессы в рамках Евразийского экономического сообщества. Вместе с тем комплекс нормативных правовых актов до сих пор содержит ряд пробелов, неточностей, сохраняет "лазейки» для нарушения прав предпринимателей, до сих пор отсутствует ясная иерархическая структура регламентов с необходимыми взаимосвязями, охватывающими все секторы применения в промышленности.
\end{abstract}

Ключевые слова: техническое регулирование, государственный надзор, актуальные проблемы, нормативно-правовая база, тенденции развития, гармонизация законодательства, систематизация законодательства, актуализация законодательства, проблемные вопросы, интеграционные процессы.

Abstract. The author considers the development of the normative-legal base of technical regulation in the context of economic development of the Russian Federation and the current problems of legislation in this sphere. Special attention is paid to the formation and improvement of the normative-legal base in the sphere of technical regulation within the integration processes in the Customs Union and the Eurasian Economic Community, the normative-legal base harmonization with the principles of the WTO, aimed at Russia's economy development and economic relations expansion. The methodology of the research is based on the dialectical and the systems methods. The author also applies such general scientific methods as analysis, synthesis, generalization, and prognostication. The author concludes that an extensive legal base has been formed recently, which promotes the formation of integrated legislation in the sphere of technical regulation; the defining factor of legislation improvement is integration within the Eurasian Economic Community. At the same time, the set of normative legal acts still contains gaps and uncertainties, allowing violations of entrepreneurs' rights; there's still a lack of a clear hierarchical structure of regulations with the necessary correlations, covering all industrial sectors they can be used in.

Key words: legislation updating, systematization of legislation, harmonization of legislation, development trends, normative-legal base, topical problems, state supervision, technical regulation, problem issues, integration processes. 


\section{Административное и муниципальное право 1 (97) 2016}

$\mathrm{H}$ ормативно-правовая база технического регулирования менялась вслед за развитием экономических условий в Российской Федерации. В начале 1990-х годов страна вошла в рынок, начался процесс всеобщей либерализации законодательства. Однако при этом законодательство оставалось ориентированным на окологосударственную коммерцию.

Правопреемником Госстандарта СССР стал Комитет Российской Федерации по стандартизации и метрологии, получивший в наследство все государственные стандарты СССР. Первые российские документы в области стандартизации были разработаны в 1992г., а в 1993г. были приняты законы «0 стандартизации»[1] и «О сертификации продукции и услуг»[2], определившие новый курс развития сферы технического регулирования.

К 2000 году нормативная база в сфере технического регулирования, устанавливающая обязательные требования, составляла свыше 60 тыс. ведомственных актов. Из них порядка 20 тыс. государственных стандартов и большое количество нормативных правовых актов, ведомственных нормативных правовых актов, большей частью принятых в 1970-1980г.

Одновременно действовали межгосударственные стандарты, государственные отраслевые стандарты, республиканские стандарты РСФСР, общесоюзные стандарты, стандарты организации и предприятий. При этом они зачастую содержали ссылки друг на друга, дублировали друг друга, а иногда и противоречили друг другу. Хотя нормотворчество было ограничено административной реформой, органы власти продолжали сами устанавливать различные ограничительные нормы и контролировать их соблюдение.

Избыточная обязательная сертификация, не соответствующие условиям рынка обязательные стандарты, игнорирование предпринимательского сообщества при процедурах принятия решений по вопросам обеспечения качества продукции тормозили развитие экономики России и расширение внешнеэкономических связей.

Все это обусловило необходимость проведения реформы в данной сфере, в результате которой должна была быть решена важнейшая задача - определение разумного баланса между обеспечением безопасности здоровья граждан, безопасности жизни, окружающей среды и снятием административных барьеров для бизнеса.

Сложившаяся система государственного контроля, как в общем, так и конкретно в сфере технического регулирования, так же вызывала большое количество претензий, связанных с неоправданным административным давлением, в связи с чем последовали меры[3] по ее модерниза- ции. В результате этого в 2001г. был принят Федеральный закон «О защите прав юридических лиц и индивидуальных предпринимателей при проведении государственного контроля (надзора)» [4] (далее - Закон № 134-ФЗ).

Впервые законодательно были установлены ограничения и общие принципы защиты прав предпринимателей при проведении надзорных мероприятий. Данным правовым актом регулировались закрепленные в Конституции РФ права и свободы человека на свободу экономической деятельности (ст. 8), свободное использование своих способностей и имущества при осуществлении предпринимательской деятельности (ст. 34), защищались права частной собственности (ст. 35).

Отправной точкой реформы законодательства о техническом регулировании стало принятие в 2002г. Федерального закона от 27.12.2002 г. № 184-Ф3 «0 техническом регулировании» [5] (далее - Закон № 184-Ф3).

Согласно статье 3 основными принципами системы технического регулирования стали:

- технические регламенты;

- стандартизация;

- подтверждения соответствия;

- государственный контроль (надзор).

Эти элементы существовали и ранее (за исключением технических регламентов), однако были существеннодоработаны и установлена необходимость соответствия технического регулирования уровню развития национальной экономики и научно-технического развития страны. При этом впервые было определено, что требования технических регламентов не должны быть препятствием осуществлению деятельности в большей степени, чем это минимально необходимо для выполнения целей технических регламентов (п. 2 ст. 7 Закона № 184-ФЗ).

С целью исключения противоречий в нормативной базе предполагалось создать систему ограниченного числа технических регламентов (от 30 до 40 регламентов), содержащих минимальные требования, вместо совершенствования существующей нормативно-технической базы.

Отечественное законодательство планировалось гармонизировать, руководствуясь принципами Всемирной торговой организации (ВТО), в соответствии с Соглашением по техническим барьерам в торговле ВТО[6], при котором при разработке отечественных регламентов должны использоваться международные стандарты.

Во главу угла законодательно было поставлено обеспечение безопасности продукции. При этом под безопасностью подразумевалось «отсутствие недопустимого риска, связанного с причинением вреда жизни или здоровью граждан, имуществу физиче- 
ских или юридических лиц, государственному или муниципальному имуществу, окружающей среде, жизни и здоровью животных и растений».

Мониторинг правоприменительной практики в 2002-2007 годах показал неэффективность механизма принятия технических регламентов, связанную с затягиванием согласования документов на межведомственном уровне, а также незначительное сокращение временных издержек хозяйствующих субъектов. Возможности применения мер технического регулирования в целях поддержки отечественных производителей нивелировались существующими обязательствами Российской Федерации, принятыми при вступлении в ВТО.

Опыт показал, что полный отказ от подзаконного нормативного регулирования и установление технических требований техническими регламентами может привести к чрезмерной зарегулированности экономической деятельности в стране. При этом значительное число нормативных правовых актов не были приведены в соответствие с Федеральным законом «О техническом регулировании», не была проведена в должной мере инвентаризация обязательных требований, не была создана однозначная методология построения нормативно-правовой базы в сфере технического регулирования.

Федеральные органы исполнительной власти зачастую продолжали работу по нормативным правовым актам, принятым еще при СССР, что существенно повлияло на правоприменительную практику.

Все это обусловило необходимость продолжения реформ[7].

В декабре 2009 г. в Закон № 184-ФЗ внесены изменения[8], направленные на упрощение процедуры разработки и принятия технических регламентов, установление возможности признания мировых стандартов для их применения, а также определены два режима технического регулирования (по выбору заявителя) на основании требований:

- российских стандартов;

- иностранных технических регламентов (стандартов, директив).

С января 2010г. вступили в действие договоренности [9] по Таможенному союзу о согласовании политики в сфере технического регулирования и максимальной гармонизации экономического пространства Республики Беларусь, Республики Казахстан и Российской Федерации. Соглашением, кроме перехода на единую систему технического регулирования в рамках Таможенного союза, предусматривалась передача полномочий по принятию технических регламентов Комиссии Таможенного союза.
За время, прошедшее с момента подписания договора о Таможенном союзе[10], была сформирована обширная правовая база, способствующая формированию единого законодательства в сфере технического регулирования на территории России, Белоруссии и Казахстана. Были приняты следующие наиболее важные документы, обеспечившие нормативную базу подготовительного этапа для принятия единых регламентов таможенного союза:

Соглашение об основах гармонизации технических регламентов государств - членов ЕврАзЭС от 24 марта 2005 года;

Соглашение о проведении согласованной политики в области технического регулирования санитарных и фитосанитарных мер от 25 января 2008 года;

Соглашение об обращении продукции, подлежащей обязательной оценке (подтверждению) соответствия, на таможенной территории таможенного союза от 11 декабря 2009 года;

Соглашение о взаимном признании аккредитации органов по сертификации (оценке (подтверждению) соответствия) и испытательных лабораторий (центров), выполняющих работы по оценке (подтверждению) соответствия, от 11 декабря 2009 года (оба соглашения ратифицированы Государственной Думой в июле 2010 года);

Решение Комиссии Таможенного союза от 17.08.2010 N 343 «0 вопросах технического регулирования в Таможенном союзе».

Все это позволило начать формировать единое правовое поле для обеспечения безопасности продукции, устранения технических барьеров, а также обеспечения защиты таможенной территории от небезопасной и фальсифицированной продукции.

С 1 января 2015 г. вступил в силу Договор о Евразийском экономическом союзе[11] и на смену Таможенному союзу пришло Единое экономическое пространство ЕврАзЭС, продолжилось расширение наднационального правового регулирования по гармонизации (сближения и унификации) национального законодательства государств - членов ЕврАзЭС[12].

Участниками союза в настоящее время являются Российская Федерация, Республика Беларусь, Республика Казахстан, Республика Армения, Киргизия.

Таким образом, сложившееся к 2015 году законодательство о техническом регулировании можно разделить на два блока:

1) законодательство Таможенного союза и ЕЭП в сфере технического регулирования:

раздел Х Договора о Евразийском экономическом союзе от 29 мая 2014 г;;

Соглашение о единых принципах и правилах технического регулирования в Республики Бела- 


\section{Административное и муниципальное право 1 (97) • 2016}

русь, Республики Казахстан и Российской Федерации от 18 ноября 2010 г.;

Единый перечень продукции, в отношении которого устанавливаются обязательные требования в рамках Таможенного союза;

Технические регламенты Таможенного союза;

2) национальное законодательство в сфере технического регулирования:

Федеральный закон от 27 декабря 2002 г. № 184-Ф3 «0 техническом регулировании»;

Единые перечни продукции, подлежащей обязательному подтверждению соответствия;

технические регламенты Российской Федерации.

Вместе с тем комплекс нормативных правовых актов до сих пор содержит ряд пробелов, неточностей, сохраняет «лазейки» для нарушения прав предпринимателей.

Отчасти на устранение этих пробелов направлен новый закон о стандартизации[13] (вступающий в силу 29.09.2015, за исключением отдельных положений), устанавливающий правовые основы стандартизации в Российской Федерации, в том числе функционирования национальной системы стандартизации. Спустя многие годы наконец-то законодательно определено понятие «технические условия». Для российского законодательства определение общего понятия «технические условия» имеет большое значение, поскольку отсылки к нему содержатся во многих актах, но до сих пор не было понятно, что под ним понимается.

Повсеместный отказ от обязательного подтверждения соответствия продукции требованиям регламента перед размещением продукции на рынке и переход на декларирование не всегда учитывает меру опасности конкретной продукции.

В настоящий момент декларацию о соответствии Таможенного союза (документ, подтверждающий соответствие продукции требованиям Таможенного союза (Единого Таможенного союза)) может принять заявитель - фирма, зарегистрированная на территории Таможенного союза в качестве юридического лица или индивидуального предпринимателя. При этом не проработан механизм по прекращению действия декларации о соответствии, принятой фирмой, зарегистрированной на территории Таможенного союза и не имеющей представительства на территории Российской федерации, отсутствует возможность привлечения такого заявителя к административной ответственности по ст. 14.44 КоАП РФ за недостоверное декларирование соответствия продукции.

Еще одной из проблем является отсутствие ясной иерархической структуры регламентов с необходимыми взаимосвязями, охватывающими все секторы применения в промышленности, что затрудняет реализацию Федерального закона «0 техническом регулировании». Например, используемые в законодательстве о техническом регулировании термины, которые применяются в законодательстве о техническом регулировании, не соответствуют терминологии, принятой в законодательстве об электроэнергетике[14], и в целом актуальной модели электроэнергетики. Отсюда система нормативных правовых и нормативно-технических актов по вопросам обеспечения сертификации электрической энергии является противоречивой. Действующие Правила проведения сертификации электрооборудования и электрической энергии[15] не учитывают изменений, произошедших в связи с реформой системы электроэнергетики. В связи с этим не представляется возможным точно определить субъекта, ответственного перед потребителями за надежность обеспечения их электрической энергией и ее качество в соответствии с требованиями технических регламентов и иными обязательными требованиями.

Особенно актуален этот вопрос в связи со складывающейся иерархией законодательства о тоническом регулировании в контексте развития единого экономического пространства стран ЕАЭС, а также разработкой Федерального закона «Об основах государственного и муниципального контроля (надзора) в Российской Федерации», предусматривающего, что предметом государственного и муниципального контроля (надзора) не может являться соблюдение обязательных требований, содержащихся в неопубликованных официально нормативных правовых актах, а также обязательных требований, установленных нормативными правовыми актами СССР и РСФСР.

Неэффективное осуществление контрольнонадзорных мероприятий отчасти вызвано как отсутствием учета вероятности причинения вреда, так и продолжением разделения надзора по отдельным свойствам и параметрам продукции. Так, в 2013 году произошло распределение полномочий[16] по контролю (надзору) за соблюдением требований Технических Регламентов Таможенного союза. При этом в отношении Технического Регламента Таможенного союза «О безопасности низковольтного оборудования» полномочия были распределены между Роспотребнадзором, в отношении низковольтного оборудования, реализуемого исключительно для личных нужд потребителей, и Росстандартом, в отношении низковольтного оборудования, реализуемого не для нужд потребителей. Похожая ситуация и с распределением полномочий в отношении технического регламента Таможенного союза «О безопасности машин и оборудования», где они были распределены между Роспотребнадзором (в отношении машин и оборудования, реализуемых исключительно для лич- 
ных нужд потребителей), Ростехнадзором (в отношении машин и оборудования, применяемых на поднадзорных Службе объектах, и связанных с требованиями к этой продукции процессов эксплуатации и утилизации) и Росстандартом (в отношении машин и оборудования, реализуемых не для нужд потребителей (за исключением машин и оборудования, применяемых на поднадзорных Ростехнадзору объектах).

Перечни стандартов, в результате применения которых на добровольной основе обеспечивается соблюдение требований технических регламентов Таможенного Союза (на нефтепродукты, низковольтное оборудование и т.д.) и осуществляется оценка (подтверждение) соответствия продукции содержат стандарты следующего вида - ГОСТ IEC, ГОСТ МЭК, ГОСТ Р ЕН, СТБ ISO, ЕН ИСО, доступ к базе этих стандартов ограничен.
Исходя из вышеизложенного можно заключить, что к настоящему моменту была проделана большая работа по систематизации и актуализации законодательства о техническом регулировании.

При этом существует значительное число проблемных вопросов, которые еще предстоит решить. В то же время необходимо отметить, что сегодня определяющим фактором совершенствования законодательства о техническом регулировании являются интеграционные процессы в рамках Евразийского экономического сообщества, а переход на единые обязательные требования в рамках ЕврАзЭС и значительная либерализация правил и процедур выпуска продукции на рынок требует установления более жесткой ответственности производителей для обеспечения высокого уровня безопасности продукции на рынке.

\section{Библиография:}

1. Закон Российской Федерации от 10 июня 1993 г. № 5154-1 «О стандартизации» // "Ведомости СНД и ВС РФ", 24.06.1993, N 25, ст. 917, "Российская газета", N 120, 25.06.1993.

2. Закон Российской Федерации от 10 июня 1993 г. № 5151-1 «0 сертификации продукции и услуг» // "Российская газета", N 120, 25.06.1993, "Ведомости СНД и ВС РФ", 01.07.1993, N 26, ст. 966.

3. Указ Президента Российской Федерации от 29 июня 1998 г. № 730 «0 мерах по устранению административных барьеров при развитии предпринимательства» // "Российская газета", N 122, 01.07.1998, "Собрание законодательства РФ", N 27, 06.07.1998, ст. 3148

4. Федеральный закон от 08.08.2001г. № 134-Ф3 «0 защите прав юридических лиц и индивидуальных предпринимателей при проведении государственного контроля (надзора)» // "Российская газета", N 155-156, 11.08.2001, "Собрание законодательства РФ", 13.08.2001, N 33 (часть I), ст. 3436

5. Федеральный закон от 27.12.2002 г. № 184-ФЗ «0 техническом регулировании» // "Собрание законодательства РФ", 30.12.2002, N 52 (ч. 1), ст. 5140

6. Agreement on technical barriers to trade [Электронный ресурс] // Режим доступа https://www.wto.org/english/ docs_e/legal_e/17-tbt.pdf - Официальный сайт Всемирной торговой организации (дата обращения: 05.04.2015).

7. Указ Президента РФ от 15 мая 2008 г. № 797 «0 неотложных мерах по ликвидации административных ограничений при осуществлении предпринимательской деятельности». // "Собрание законодательства РФ", 19.05.2008, N 20, ст. 2293

8. Федеральный закон Российской Федерации от 30 декабря 2009 г. N 385-Ф3 "0 внесении изменений в Федеральный закон "О техническом регулировании"" // "Собрание законодательства РФ", 04.01.2010, N 1, ст. 6

9. Соглашение о единых принципах и правилах технического регулирования в Республике Беларусь, Республике Казахстан и Российской Федерации от 18.11.2010г. // "Собрание законодательства РФ", 30.01.2012, N 5, ст. 536

10. "Договор о Таможенном союзе и Едином экономическом пространстве" (подписан в г. Москве 26.02.1999) // Собрание законодательства РФ. 2001. N 42. Ст. 3983.

11. "Договор о Евразийском экономическом союзе" (подписан в г. Астане 29.05.2014) Договор об учреждении Евразийского экономического сообщества (подписан в г. Астане 10 октября 2000 года) // Официальный интернетпортал правовой информации http://www.pravo.gov.ru, 16.01.2015.

12. Решение Межгосударственного Совета ЕврАзЭС от 31 мая 2001 года N 3 "О Положении о Межгосударственном Совете Евразийского экономического сообщества". [Электронный ресурс] // Режим доступа: http://www.evrazes. eom/docs/view/5 - Официальный сайт Евразийского экономического сообщества (дата обращения: 25.08.2014).

13. Федеральный закон от 29.06.2015 N 162-Ф3 "О стандартизации в Российской Федерации" // "Собрание законодательства РФ", 06.07.2015, N 27, ст. 3953

14. Федеральный закон от 26.03.2003 N 35-Ф3 "Об электроэнергетике" // "Собрание законодательства РФ", 31.03.2003, N 13, ст. 1177

15. Правила проведения сертификации электрооборудования и электрической энергии . Утверждены с Изменением №1 Постановлением Госстандарта России от 3.01.2001 г. и зарегистрированы в Министерстве юстиции РФ 14 02.2001 г., рег. № 2576

16. Постановление Правительства Российской Федерации от 13 мая 2013 г. N 407 "Об уполномоченных органах Российской Федерации по обеспечению государственного контроля (надзора) за соблюдением требований технических регламентов Таможенного союза" // "Собрание законодательства РФ", 20.05.2013, N 20, ст. 2501.

17. Котляров Ю.В. Правоприменительные аспекты применения мер государственного принуждения в сфере технического регулирования // Финансовое право и управление. - 2015. - 2. - C. 273 - 278. DOI: 10.7256/23100508.2015.2.15871. 


\section{Административное и муниципальное право 1 (97) • 2016}

18. Калюжная Д.Е. Становление глобальной экологической политики: достижения, промахи и риски // Право и политика. - 2013. - 9. - С. 1182 - 1194. DOI: 10.7256/1811-9018.2013.9.9216.

19. Уткин В.В. Административно-правовое регулирование в сфере стандартизации как фактор повышения конкурентоспособности отечественного бизнеса // Финансовое право и управление. - 2015. - 3. - C. 319 - 325. DOI: 10.7256/2310-0508.2015.3.16279.

\section{References (transliterated):}

1. Zakon Rossiiskoi Federatsii ot 10 iyunya 1993 g. № 5154-1 «0 standartizatsii» // "Vedomosti SND i VS RF", 24.06.1993, N 25, st. 917, "Rossiiskaya gazeta", N 120, 25.06.1993.

2. Zakon Rossiiskoi Federatsii ot 10 iyunya 1993 g. № 5151-1 «O sertifikatsii produktsii i uslug» // "Rossiiskaya gazeta", N 120, 25.06.1993, "Vedomosti SND i VS RF", 01.07.1993, N 26, st. 966.

3. Ukaz Prezidenta Rossiiskoi Federatsii ot 29 iyunya 1998 g. № 730 «0 merakh po ustraneniyu administrativnykh bar'erov pri razvitii predprinimatel'stva» // "Rossiiskaya gazeta", N 122, 01.07.1998, "Sobranie zakonodatel'stva RF", N 27, 06.07.1998, st. 3148

4. Federal'nyi zakon ot 08.08.2001g. № 134-FZ «O zashchite prav yuridicheskikh lits i individual'nykh predprinimatelei pri provedenii gosudarstvennogo kontrolya (nadzora)»// "Rossiiskaya gazeta", N 155-156, 11.08.2001, "Sobranie zakonodatel'stva RF", 13.08.2001, N 33 (chast' I), st. 3436

5. Federal'nyi zakon ot 27.12.2002 g. № 184-FZ «O tekhnicheskom regulirovanii» // "Sobranie zakonodatel'stva RF", 30.12.2002, N 52 (ch. 1), st. 5140

6. Agreement on technical barriers to trade [Elektronnyi resurs] // Rezhim dostupa https://www.wto.org/english/docs_e/ legal_e/17-tbt.pdf - Ofitsial'nyi sait Vsemirnoi torgovoi organizatsii (data obrashcheniya: 05.04.2015).

7. Ukaz Prezidenta RF ot 15 maya 2008 g. № 797 «0 neotlozhnykh merakh po likvidatsii administrativnykh ogranichenii pri osushchestvlenii predprinimatel'skoi deyatel'nosti». // "Sobranie zakonodatel'stva RF", 19.05.2008, N 20, st. 2293

8. Federal'nyi zakon Rossiiskoi Federatsii ot 30 dekabrya 2009 g. N 385-FZ "O vnesenii izmenenii v Federal'nyi zakon "O tekhnicheskom regulirovanii"" // "Sobranie zakonodatel'stva RF", 04.01.2010, N 1, st. 6

9. Soglashenie o edinykh printsipakh i pravilakh tekhnicheskogo regulirovaniya v Respublike Belarus', Respublike Kazakhstan i Rossiiskoi Federatsii ot 18.11.2010g. // "Sobranie zakonodatel'stva RF", 30.01.2012, N 5, st. 536

10. "Dogovor o Tamozhennom soyuze i Edinom ekonomicheskom prostranstve" (podpisan v g. Moskve 26.02.1999) // Sobranie zakonodatel'stva RF. 2001. N 42. St. 3983.

11. "Dogovor o Evraziiskom ekonomicheskom soyuze" (podpisan v g. Astane 29.05.2014) Dogovor ob uchrezhdenii Evraziiskogo ekonomicheskogo soobshchestva (podpisan v g. Astane 10 oktyabrya 2000 goda) // Ofitsial'nyi internetportal pravovoi informatsii http://www.pravo.gov.ru, 16.01.2015.

12. Reshenie Mezhgosudarstvennogo Soveta EvrAzES ot 31 maya 2001 goda N 3 "O Polozhenii o Mezhgosudarstvennom Sovete Evraziiskogo ekonomicheskogo soobshchestva". [Elektronnyi resurs] // Rezhim dostupa: http://www.evrazes. eom/docs/view/5 - Ofitsial'nyi sait Evraziiskogo ekonomicheskogo soobshchestva (data obrashcheniya: 25.08.2014).

13. Federal'nyi zakon ot 29.06.2015 N 162-FZ "O standartizatsii v Rossiiskoi Federatsii" // "Sobranie zakonodatel'stva RF", 06.07.2015, N 27, st. 3953

14. Federal'nyi zakon ot 26.03.2003 N 35-FZ "Ob elektroenergetike" // "Sobranie zakonodatel'stva RF", 31.03.2003, N 13, st. 1177

15. Pravila provedeniya sertifikatsii elektrooborudovaniya i elektricheskoi energii . Utverzhdeny s Izmeneniem №1 Postanovleniem Gosstandarta Rossii ot 3.01.2001 g. i zaregistrirovany v Ministerstve yustitsii RF 1402.2001 g., reg. № 2576

16. Postanovlenie Pravitel'stva Rossiiskoi Federatsii ot 13 maya 2013 g. N 407 "Ob upolnomochennykh organakh Rossiiskoi Federatsii po obespecheniyu gosudarstvennogo kontrolya (nadzora) za soblyudeniem trebovanii tekhnicheskikh reglamentov Tamozhennogo soyuza" // "Sobranie zakonodatel'stva RF", 20.05.2013, N 20, st. 2501.

17. Kotlyarov Yu.V. Pravoprimenitel'nye aspekty primeneniya mer gosudarstvennogo prinuzhdeniya v sfere tekhnicheskogo regulirovaniya // Finansovoe pravo i upravlenie. - 2015. - 2. - C. 273 - 278. DOI: 10.7256/2310-0508.2015.2.15871.

18. Kalyuzhnaya D.E. Stanovlenie global'noi ekologicheskoi politiki: dostizheniya, promakhi i riski // Pravo i politika. - 2013. - 9. - C. 1182 - 1194. DOI: 10.7256/1811-9018.2013.9.9216.

19. Utkin V.V. Administrativno-pravovoe regulirovanie v sfere standartizatsii kak faktor povysheniya konkurentosposobnosti otechestvennogo biznesa // Finansovoe pravo i upravlenie. - 2015. - 3. - C. 319 - 325. DOI: 10.7256/23100508.2015.3.16279. 